Available online at: $\mathrm{http}: / /$ proceeding.rsfpress.com/index.php/pss/index

LPPM UPN “Veteran” Yogyakarta Conference Series

Proceeding on Political and Social Science (PSS)

Volume 1 Number 1 (2020): 273-281

\title{
Measuring The Effectiveness Of Influence In Digital Public Diplomacy
}

\author{
Iva Rachmawati, Frans Richard Kodong, Yuseptia Angretnowati \\ Universitas Pembangunan Nasional Veteran Yogyakarta \\ E-mail address iva.rachmawati@upnyk.ac.id E-mail address frkodong@gmail.com \\ E-mail address yuseptia@gmail.com
}

\begin{abstract}
Measuring the influence of public diplomacy is still often questioned in public diplomacy studies. Apart from not being easy to connect public diplomacy efforts and changes in perceptions or behavior, public diplomacy measures tend to require high costs research or evaluation. However, digital technology that brings public diplomacy practices into the virtual space impacts the way of public diplomacy evaluation or measurement. . This article offers an argument that the impact or influence of digital public diplomacy can also be measured even though there is no face to face meeting. By considering the agendasetting, presence expansion, and conversation generating that is happening on Twitter belonging to the Ministry of Foreign Affairs and the Embassy, it is possible to measure how deep the mutual understanding, collaboration, and engagement are taking place. Without conducting surveys or interviews, the researcher could know the effectiveness of digital public diplomacy influence more quickly and cheaply.
\end{abstract}

Keywords: Digital Public Diplomacy, Measurement

\section{INTRODUCTION}

This is an open access article under the CC-BY-NC license.

Van Ham (2005: 9) admits that the most severe difficulty from public diplomacy measures the success of persuasion, perceptions, and the willingness of a person or group of people to accept new ideas. According to Nye, this happens because there will always be a gap between the resource/input and power outcome. More specifically, these resources do not always show the desired outcome directly. The gap between resource and power outcome does not only happen to soft power but also to hard power (Seichi, 2008: 219). Matwiczak (2010: 13) confirms this opinion by arguing that factors of public diplomacy activities held abroad, which may cause changes to the audience, cannot be ignored. Public diplomacy is not contained in a vacuum; therefore, other factors may impact changing perceptions or behavior. Thus, it's not easy to firmly claim that the change of perception caused by public diplomacy. 
Several academics acknowledge the difficulty of measuring the impact of public diplomacy. The difficulties are partly because 1 . there are various sources of information that can be obtained by the government which are the basis for changes in their foreign policy so that it is not easy to determine which persuasion has a significant impact on changing policy, 2 . it takes time that does not briefly to see the effect of persuasion being carried out so that when the results are obtained, the influential situation or foreign policy has changed, 3. research on the impact of diplomacy is carried out through surveys, in-depth interviews or focus group discussions, which means that it requires a lot of researchers to carry out these activities. As a result, there are few costs incurred to carry out evaluations, 4 . the research methods carried out are prone to actors and respondents (Bolgov et al., 2016; Banks, 2011; Layne, 2010).

Even though it is difficult to do, many countries still carry out this measurement to obtain public diplomacy activities - evaluating public diplomacy is government responsibility to the taxpayers. Interview, survey, poll, and focus group discussion methods are frequently used to analyze and measure the performance of public diplomacy. For example, the United Kingdom used the logic model to measure public diplomacy's success by comparing work plans with results (Wilding, 2007). Australia uses the DFAT model, which is based on interviews and opinion surveys (Parliament of Australia. 2007). Meanwhile, the United States of America uses several measurements, ranging from quantitative ones with the Public Diplomacy Model for the Assessment of Performance (PD-MAP) (Matwiczak, 2010) and the Assessment Rating Tool (PART) Program to survey methods through the Advancing Public Diplomacy Impact (APDI). (Banks, 2011).

Along with the development of digital technology, some public diplomacy practices have shifted to new media spaces. This situation leads to the need for a different measurement method. Social media diplomacy, which is believed to be able to spread values and culture more quickly (Van Ham, 2010: 134), on the other hand, provides challenges in measuring the impact of activities in related social media. The challenge due, among other things, not identifying the identity of netizens or accounts that are anonymous. This situation is rather tricky for digital public diplomacy to foster 'trust' as a capital for mutual understanding and even engagement (Correa et al. 2015).

The widespread practice of public diplomacy in digital spaces needs a particular measurement to evaluate the result of digital public diplomacy work. Measuring online activity certainly requires many adjustments because not all respondents can be interviewed, considering that several accounts are anonymous. This article presents some considerations on measures that can be used to assess how deeply digital public diplomacy can carry out traditional public diplomacy functions. Those include the emergence of an understanding of the information conveyed or mutual understanding and mutual engagement or support for activities or ideas offered in content/uploads. This article also provides an argumentation to quickly assess an account's performance in conducting digital public diplomacy. 


\section{LITERATURE REVIEW}

The widespread use of digital technology by the public impacts their expanding influence on international discourse, encouraging public diplomacy to adopt social media facilities to support its activities. As part of public diplomacy, social media to build individual perceptions in the international public has led some academics to interpret digital diplomacy in a narrow sense, namely diplomatic activities using social media. Social media provides a platform for unconditional communication and has become a powerful communicator's tool. There are various kinds of social media that international actors use, but the most popular are Twitter, Facebook, Instagram, YouTube, Periscope, and Snapchat. Social media allows the state to communicate directly with the public and disseminate information quickly. Information can even be doubled when the public re-uploads the information content. The influence will be even more substantial when the public re-uploads and gives positive comments because public trust has grown in the related content. (Holmes,2013: 6) and (Hanson,2011) notes on the e-diplomacy show that e diplomacy is diplomacy carried out through social media. Networks that can be generated by social media are one of the reasons for diplomats to start disseminating information using the internet.

Apart from efficiently disseminating information, social media also allows the public, who previously were only the target of diplomacy, to become part of the diplomatic effort. The breadth of knowledge and moving in virtual space results in a freer situation for anyone who enters it. Thanks to the low cost, social media users are increasingly active in seeking information and processing their data. They have the ability to deliver their own opinions and open up new communications in the public arena. The government, which does not want to lose relevance and valuable access, is starting to provide opportunities for public participation in deliberately opened and organized spaces. Thus, government efforts emerged to foster mutual understanding, engagement, cooperation, or collaboration on social networks.

This kind of effort is deeply embedded in public diplomacy, where the government must manage its relationship with the public to promote policy agendas and policy change. If public diplomacy adopts social media, these efforts will move from offline to online. Many platforms were created to reach out to the public and build public perceptions in line with the government's goals. Building perceptions in line with the government's goals is certainly not easy. Social media provides an excellent opportunity for the public to express their political views, so it is not uncommon for social media to become a media for contesting state policies.

A narrow understanding of digital diplomacy is also proposed by (Manor and Segev,2015), which defines digital diplomacy as using social media by the state to gain its foreign interests and manage its national image. They note that digital diplomacy exists at two levels: foreign ministries and embassies located worldwide. By operating at these two levels, the state can disseminate foreign policy and influence the public at home and abroad. It can adapt foreign policies and messages to local audiences' unique characteristics concerning history, culture, values, and traditions. On the other hand, the government can obtain opinions and responses on disseminating information and images that they promote. 
The social media platform allows anyone to communicate, so digital diplomacy brings diplomats to communicate directly with other diplomats and the public regarding foreign policy or additional information related to diplomatic activities and international issues. Raschika (2018) mentioned that social media allows diplomats to observe events, gather information, and identify key influencers. They also provide a channel to influence netizens through traditional means. They can assist in the consultation process, formulate policies, and help share ideas. Through social media, netizens can (1) interact with messages on the same platform, (2) spread their content, and (3) create their network (Arsenault, 2009). Rybalko and Seltzer (2010) believe that websites and social networks provide useful information to the public and are easy to use. Lewis (2014) defines digital diplomacy as using digital communication tools (social media) by diplomats to communicate with each other and with the general public.

Social media facilities that allow each participant to exchange messages, ideas, or opinions make it seem as if they can meet in person, especially when social media has facilities for conducting video calls or video conferences, podcasts, etc. (Richard H. Solomon, 1997), president of the United States Institute of Peace (USIP), called it virtual diplomacy, namely "social, economic, and political interactions that are mediated through electronics." Although not real (direct), virtual diplomacy is real diplomacy - in the sense that there are authoritative interactions between different government officials. Meanwhile, the Virtual Diplomacy Initiative defines virtual diplomacy as a change in diplomacy related to a global network's emergence. This term includes decision-making, coordination, communication, and practice of international relations carried out with the help of information and communication technology "(United States Institute of Peace, 2006).

(Meanwhile, Smith ,1999) indicates that virtual space is increasingly providing opportunities for everyone to become a diplomat for their interests in capturing social media platforms, enabling everyone to participate in expressing their opinions or opinions. It defines virtual diplomacy as the behavior of what has been considered classical diplomacy in the past. Still, it is now an activity that is carried out differently because of changes in technology and because it is being practiced by more people, including many who are not professional diplomats.

\section{RESEARCH METHODOLOGY}

This article's research method is qualitative, namely by using several papers and documents supporting arguments. A qualitative research method is a research that intends to understand the phenomena experienced by research subjects. For example, behavior, perception, motivation, action, etc., holistically, and utilizing descriptions in the form of words and language, in a specific natural context, and by using various natural methods (Moleong, 2005: 6). A reference is a research article about using some features owned by social media that users can use to show their responses to content uploaded by users Using ( Bjola and Jiang's Comparative Analysis, 2015), to find out the depth of mutual understanding, collaboration, and engagement. The research used Twitter belonging to the Indonesian 
Embassy and the Indonesian Ministry of Foreign Affairs as a basis for consideration for the formation/compilation of measurements.

\section{FINDING AND DISCUSSION}

The impact of digital public diplomacy can be studied through 3 things to find out how much mutual understanding, collaboration, and engagement are taking place. This measurement was conducted by looking at the agenda-setting, presence expansion, and conversation generating on Twitter. First, to find out how effective the agenda-setting is, it can be measured by the number of "likes" obtained through each upload. Before counting the number of "likes," which can be interpreted as approval or support towards the content, the researcher must establish the agenda-setting in advance. The classification of agenda-setting referring to the objectives of public diplomacy, namely:

1. Service functions/protection of Indonesian citizens classified through keywords related to diplomatic services. Currently, document processing at the Indonesian Embassy or Indonesian Consulate can be done online. Examples of keywords that can be used (can be with hashtags or without hashtags) include 'Document,' 'WNI,' and \#NegaraMelindung, \# Covid19.

2. The function of negotiating classified through keywords related to diplomacy carried out by countries for example, 'Diplomatic Relations,' 'Bilateral Relations' and 'Cooperation' and \#IniDiplomasi, \#SahabatKemlu, \#MenluRetno, \#FMMarsudi, \#RintisKemajuan progress, \#BatikDiplomacy, \# IndonesianWay, \#DigitalDiplomacy. \#DiplomasiCulinary.

3. Information function regarding Indonesia's role and attitude in the international world classified through keywords related to state policies related to international phenomena such as 'United Nations,' 'ASEAN,' 'Multilateral Cooperation.' 'Rohingya'; 'Palestine', 'Syria'. 'Iraq', 'ISIS', and the hashtags \#IndonesiaUntukDunia, \#CounterTerrorism. \#DiplomacyforPeaceand Prosperity. In addition to information about international phenomena, domestic issues can also attract world attention. Related to Indonesia, keywords that can be used are, for example, 'Papua,' 'Palm Oil,' 'Border' and 'Indonesian Democracy' and the hashtag \#BaliDemocracyForum

The number of "like" in each upload shows whether the content is quite popular or not. The number of "likes" also shows the mutual understanding aspect amongst the netizen toward the contents. The total number of likes obtained compared to the number of followers that the account has on shows how high or low the understanding is obtained from netizens and account owners.

Second, to find out the high or low level of collaboration will be determined by how many times each keyword is retweeted or re-uploaded. It can also help determine what messages are re-uploaded most frequently to select the public's preference for re-uploads of messages. The retweet or re-uploads also shows the breadth or presence expansion. (Sevin and Ingehoff 2018) conducted research to determine how retweets were carried out and by anyone to 
assess the extent of public diplomacy's impact on specific topics by four countries. This research can analyze the distribution and number of retweets per upload. Thus, this method can be borrowed to assess the depth of collaboration that occurs and on what content high or low distribution occurs.

From the keywords created, it can also be determined how often conversation generating or dialogue/response occurs in comments to measure engagement. The more comments and reactions by the admin show the success of generating conversation generating. From this measurement, it can also be seen which agendas have high conversations and which are not. New media such as Twitter allow for immediate feedback. Instant feedback is made possible with the reply feature on Twitter, which can be received directly by the account mentioned in a notification. Nasrullah interpreted interactivity in the new media as the change in netizens as objects that were the target of the message but had an important role, namely being the subject. Changes in the medium's meaning have renewed the audience's position to be more interactive with the message (Nasrullah, 2016: 14).

Although not directly interacting, interaction via computer media still meets the communication criteria referred to as Computer-Mediated Communication (CMC) or computer-mediated communication. The communication process between the Indonesian Embassy or the Ministry of Foreign Affairs and its audiences, both in the interests of news distribution and a two-way communication medium, is mediated by technology designed, created, and used to enable data exchange information. This communication is part of CMC because it fulfills CMC's aspects, as expressed by (Marc Smith (1995, in Nasrullah, 2016). First, contact or interaction in the cyber world does not require the existence and similarity between cyber media users when the interaction function takes place. Interactions do not have to be in the same place and time as face-to-face or telephone communication. Indonesian Embassy and Ministry of Foreign Affairs can send messages from anywhere as long as they are connected to a computer or the internet, and so can their audience. At any time, these interactions can occur. The Indonesian Embassy or the Ministry of Foreign Affairs can issue a tweet in the morning, then the audience can respond during the day. The Indonesian Embassy or the Ministry of Foreign Affairs can reply to the response at night, and the communication can still occur.

\section{CONCLUSION AND FURTHER RESEARCH}

Digital technology has provided an opportunity to measure and assess the impact of public diplomacy performance more easily and quickly. In digital public diplomacy held through social media, we can still find several interactions and responses that can be used to measure the effectiveness of public diplomacy performance, including agenda setting, presence expansion, and conversation generating. Features on social media such as Twitter allow the measurement to be carried out. Twitter provides a like button to show agreement or mutual understanding. The retweet feature offers expansion and the depth of collaboration and conversation degenerating or dialogue opportunities to occur as the beginning of the engagement. 
However, the method of measuring digital public diplomacy involves big data. It needs other methods such as the Opinion Mining method to summarize and assess large amounts of data. The next research can use the Opinion Mining method in measuring agenda setting, presence expansion, and conversation generating. Thus, the proposed method can become an alternative besides survey and interview methods such as those carried out in APDI, PART, PD-MAP, and Logic Model.

\section{REFERENCES}

Banks, Robert. 2011. A Resource Guide to Public Diplomacy Evaluation. Los Angeles: Figueroa Press.

Bjola, Corneliu, and Lu Jiang. 2015. "Social Media and Public Diplomacy: A Comparative Analysis of the Digital Diplomatic Strategies of the E.U., U.S., and Japan in China." Dalam Corneliu Bjola dan Marcus Holmes (eds.) .Digital Diplomacy: Theory and Practice, London and New York: Routledge

Bolgov, Radomir, Sergey Bogdanovich, Vatanyar Yag'ya, and Marina Ermolina. 2016. "How to Measure Digital Diplomacy Efficiency: Problems and Constraints." Springer International Publishing. DOI: 10.1007/978-3-319-49700-6_18.

Chen, Po-chi. 2012. " Public Diplomacy as China's Smart Power Strategy in an Information Age: Case Study of Anti-Carrefour Incident in 2008". International Journal of China $\begin{array}{llllll}\text { Studies. } & \text { Vol. } & 3 & \end{array}$ https://mountainrunner.us/2010/10/a_notional_model_for_evaluatin/

Correa, Denzil, Leandro Araújo Silva, Minack Mondal, Fabrício Benevenuto, Krishna P. Gummadi. 2015. "The Many Shades of Anonymity: Characterizing Anonymous Social Media Content." International AAAI Conference on Web and Social Media (ICWSM).

Cowan, Geoffrey, and Amelia Arsenault. 2008. "Moving from Monolog to Dialogue to Collaboration: The Three Layers of Public Diplomacy." Annals of the American Academy of Political and Social Science, Vol. 616. Sage Publications

Eddyono, Subarkah, A. 2013. "Twitter: Kawan, Sekaligus Lawan Bagi Redaksi Berita". Journal Communication Spectrum, 3 (1), http://jurnal.bakrie.ac.id/index.php/Journal_Communication_spectrum/article/view/766.

Fitzpatrick, Kathy R. 2010." U.S. Public Diplomacy's Neglected Domestic Mandate." CPD Perspective on Public Diplomacy Paper 3. USC Center on Public Diplomacy: the Annenberg School.

Ham, Peter Van. 2005. "Power, Public Diplomacy, and the Pax Americana." Dalam Jan Melissen. The New Public Diplomacy, Soft Power in International Relations. New York: Palgrave McMillan.

Hanson, F. 2012. Baked In And Wired: Ediplomacy@State, Foreign Policy Paper Series No 30 (Pp. 1-41), Washington, Dc: Brookings Institution.

Holmes, Marcus, Ph.D. 2013. "What Is e-Diplomacy?"-Paper Prepared For The 2013 7theuropean Consortium For Political Research General Conference In Bordeaux.

Kent, M. L., \& Taylor, M.2018. "Building Dialogic Relationships Through The World Wide Web." Public Relations Review, 24(3).

Layne, Christopher. 2010. "The Unbearable Lightness of Soft Power." Dalam Inderjeet Parmar and Michael Cox ed. Soft Power and U.S. Foreign Policy Theoretical, Historical and Contemporary Perspectives. New York: Routledge. 
Lewis, Dev. 2014. "Digital Diplomacy." http://www.gatewayhouse.in/\%20digitaldiplomacy-2/

Manor, I., and C. Segev. 2015." America's Selfie: How The U.S. Portrays Itself On Its Social Media Accounts." in Bjola, C, and Holmes, M. (eds) Digital Diplomacy: Theory and Practice. New York: Routledge.

Matwiczak, Kenneth PhD. 2010. "Public Diplomacy Model for the Assessment of Performance." Policy Research Project Report Number 170. Lyndon B. Johnson School of Public Affairs. ISBN 978-0-89940-788-3.

McCombs, M. E. 2004. Setting the agenda: the mass media and public opinion. Malden, MA: Blackwell Publishing, Inc.

McQuail, D. 2008. McQuail's Mass Communication Theory (5 ed.). London: SAGE Publications Ltd.

Melissen, Jan. 2005. "The New Public Diplomacy: Between Theory and Practice," in Jan Melissen (Ed.), The New Public Diplomacy: Soft Power in International Relations Houndmills: Palgrave Macmillan.

Nasrullah, Rulli, Dr. M.Si., 2014. Teori dan Riset Media Siber. Yogyakarta: kaki Langit Kencana.

Pamment, James. 2013. New Public Diplomacy In The 21st Century: a Comparative Study of Policy And Practice. Routledge New Diplomacy Studies. London; New York: Routledge.

Parliament of Australia. 2007. "Chapter 13 - The evaluation of Australia's public diplomacy programs".

https://www.aph.gov.au/Parliamentary_Business/\%20Committees/Senate/Foreign_Affai rs_Defence_and Trade/Completed inquiries/2004-

07/public diplomacy/report/c13\%20.

Rauschnabel, Philipp A. Pavica Sheldon, and Erna Herzfeld. 2019. "What Motivates Users to Hashtag on Social Media?". Psychology and Marketing.

Renken, Wiekke. 2014. "Social Media Use in Public Diplomacy A Case Study of the German Missions' Facebook use Thesis MSc in Strategic Public Relations." Thesis. Lund University.

Rybalko, S., \& Seltzer, T. 2010. "Dialogic Communication in 140 Characters or less: How Fortune 500 Companies Engage Stakeholders Using Twitter". Public Relations Review. 36 (4), 336-341.

Seiichi, Kondo. 2008. "Wielding Soft Power The Key Stages of Transmission and Reception." Dalam Watanabe Yasushi dan David L. McConnell, ed. 2008. Soft Power Superpowers Cultural and National Assets of Japan and the United States. New York: M.E.Sharpe Inc.

Sevin, Efe, and Usadiana Ingenhoff. 2018. "Public Diplomacy On Social Media: Analyzing Networks And Content." International Journal Of Communication. 12(2018), 3663-3685.

Solomon, Richard H. (1997). The Information Revolution And International Conflict Management [Online]. United States Institute Of Peace. https://www.usip.org/Pubs/Peaceworks/\%20Virtual18/Inforev_18.Html.

Smith, Gordon S. 1999. Reinventing Diplomacy: A Virtual Necessity [Online]. United States Institute Of Peace. Available 
Http://Www.Usip.Org/Virtualdiplomacy/Publications/Reports/Gsmithisa99.Html\#Note 1.

Theunissen, P., \& Wan Noordin, W. N. 2012. "Revisiting The Concept "Dialogue" In Public Relations." Public Relations Review, 38(1). Elsevier.

Wilding, Colin M. 2007. Measuring The Effectiveness Of Public Diplomacy: The U.K. Approach.

Wolfsfeld1, Gadi, Elad Segev dan Tamir Sheafer. 2013. "Social Media and the Arab Spring: Politics Comes First." The International Journal of Press/Politics 18(2). 